\title{
FAKTOR - FAKTOR YANG DIDUGA MENJADI PREDIKTOR TERJADINYA PENINGKATAN TEKANAN DARAH SISTOLIK PADA PENDERITA HIPERTENSI
}

\author{
Riza Fikriana \\ Sekolah Tinggi Ilmu Kesehatan Kepanjen Malang \\ JL. Trunojoyo No 16 Kepanjen Malang 65163 \\ Email : riza_fikriana@stikeskepanjen-pemkabmalang.ac.id
}

\begin{abstract}
Hypertension is one of the disease which is increasing in numbers every years. These need serious attention because hypertension cause cardiac attack. The aim of this study is to identify predictors suspected factors increasing systolic blood pressure in hypertension. The study design used correlational research with analytic cross-sectional study analysis. Samples are 42 participants in Desa Trenyang RW 09 Sumberpucung Malang which taken by purpossive sampling. Data were analysed with logistic regression test. The result showed that family history have the highest effect in increasing systolic blood pressure ( $p$-value 0,26$)$. Both of body mass index ( $p$-value 0,47$)$ and sugar consumption ( $p$-value 0,5) also give an effect in systolic blood pressure. Based on the family history result, body mass index, and sugar consumption can increase systolic blood pressure, so it is very important for hypertensien patient to get healthy life to prevent uncontrolled blood pressure and to prevent many complication.
\end{abstract}

Keywords : blood pressure, hypertension

Abstrak : Hipertensi merupakan salah satu penyakit dengan jumlah penderita yang terus meningkat setiap tahunnya. Penyakit ini perlu mendapatkan perhatian yang serius karena dapat menyebabkan terjadiya serangan jantung. Tujuan penelitian ini adalah mengidentifikasi faktor - faktor yang diduga menjadi prediktor terjadinya peningkatan tekanan darah sistolik pada penderita hipertensi. Desain penelitian menggunakan penelitian korelasional dengan analytic cross sectional study. Sampel diambil secara purpossive sampling dari penderita hipertensi di Desa Trenyang RW 09 Sumberpucung Malang dengan jumlah 42 orang. Hasil uji regresi logistik didapatkan bahwa variabel yang paling berpengaruh terhadap peningkatan tekanan darah sistolik adalah riwayat keluarga dengan $p$-value sebesar 0,26 . Selanjutnya variabel Indeks Massa Tubuh (IMT) dengan $p$-value 0,47 dan variabel pola konsumsi manis dengan $\mathrm{p}$-value 0,5 . Berdasarkan hal tersebut diketahui bahwa riwayat keluarga, IMT dan konsumsi manis akan dapat meningkatkan tekanan darah sehingga perlu kiranya bagi penderita hipertensi untuk melakukan pola hidup sehat agar terhindar dari peningkatan tekanan darah tidak terkontrol dan mencegah terjadinya komplikasi.

Kata kunci : tekanan darah, hipertensi

\section{PENDAHULUAN}

Hipertensi merupakan salah satu penyakit yang jumlahnya terus mengalami peningkatan setiap tahunnya. Diperkirakan jumlah penderita hipertensi di dunia saat ini mencapai 970 juta. Angka ini diprediksi akan terus mengalami peningkatan. Diperkirakan pada tahun 2025 akan mencapai 1,56 milyar penduduk yang menderita hipertensi (Bell Kayce et al, 2015) . Sedangkan di Indonesia, berdasarkan pada hasil riset kesehatan dasar tahun 2013 didapatkan bahwa sebagian besar masalah hipertensi di masyarakat belum terdiagnosis. Hal ini dibuktikan dengan prevalensi hipertensi pada penduduk di Indonesia umur $>18$ tahun berdasarkan hasil diagnosis tenaga kesehatan sebesar 9,4\% dan berdasarkan hasil pengukuran tekanan darah sebesar 25,8\% (Kemenkes Ri, 2013).

Secara keseluruhan, penyakit ini dapat terjadi pada laki - laki dan perempuan dengan proporsi yang sama. Akan tetapi jika dilihat dari usia, jumlah hipertensi akan meningkat sesuai dengan peningkatan umur seseorang. Pada usia kurang dari 45 tahun, hipertensi banyak diderita oleh laki - laki dibandingkan dengan perempuan. Sedangkan pada usia lebih dari 65 tahun, prevalensinya banyak terjadi pada perempuan (Bell Kayce et al, 2015) . 
Upaya pencegahan terhadap kekambuhan dan pengobatan penyakit hipertensi perlu dilakukan untuk mencegah terjadinya komplikasi dari hipertensi. Perubahan gaya hidup seorang penderita hipertensi yang meliputi diet sehat seperti membatasi asupan makanan berlemak dan manis, meningkatkan akitivitas fisik yaitu melakukan olahraga rutin, mengurangi tingkat stress, mengurangi atau menghindari penggunaan rokok dan alkohol merupakan faktor penting untuk menjaga tekanan darah penderita hipertensi (Bickley. Lynn S, 2015). Dengan melakukan modifikasi pola hidup sehat, akan meminimalkan terjadinya komplikasi dari penyakit hipertensi seperti serangan jantung, stroke, gagal ginjal kronis maupun gagal jantung (Saputra Lyndon, 2014).

Menurut Ratih Maharani selaku Kepala Bidang Program Pelayanan Kesehatan Masyarakat Dinas Kesehatan Kabupaten Malang, wilayah Kabupaten Malang juga merupakan daerah dengan penduduk hipertensi cukup tinggi. Adanya penyakit hipertensi ini merupakan salah satu faktor yang menyebabkan terjadinya serangan jantung. Pada tahun 2015, di wilayah Kabupaten Malang terdapat 5.398 orang yang mengalami jantung bermasalah, salah satunya yaitu hipertensi (Jawa Pos, 2016). Berdasar hasil studi pendahuluan yang dilakukan di RW 09 Desa Trenyang Sumberpucung, didapatkan data jumlah penduduk yang mengalami hipertensi sebanyak 45 orang.

Berdasarkan latar belakang di atas, maka peneliti tertarik untuk mengadakan penelitian tentang faktor - faktor yang berhubungan dengan terjadinya peningkatan tekanan darah sistolik pada penderita hipertensi di RW 09 Desa Trenyang Sumberpucung Malang. Tujuan penelitian ini adalah untuk mengidentifikasi faktor - faktor yang di duga menjadi prediktor terjadinya peningkatan tekanan darah sistolik penderita hipertensi yang meliputi faktor usia, jenis kelamin, Indeks Massa Tubuh (IMT), riwayat keluarga, pola konsumsi lemak, pola konsumsi manis, pola aktivitas, tingkat kecemasan, dan konsumsi rokok.

\section{METODE PENELITIAN}

Desain penelitian yang digunakan merupakan penelitian korelasional dengan pendekatan cross sectional. Populasi dalam penelitian ini adalah seluruh penderita hipertensi yang ada di wilayah RW 09 Desa Trenyang Sumberpucung Kabupaten Malang yang berjumlah 45 orang. Selanjutnya diambil sampel penelitian dengan teknik purpossive sampling sebanyak 42 orang. Instrumen penelitian menggunakan kuisioner yang berisikan pertanyaan - pertanyaan tentang karakteristik responden dan pola hidup sehari - hari yang berhubungan dengan hipertensi. Data yang diambil antara lain usia, jenis kelamin, riwayat keluarga, indeks massa tubuh (IMT), pola konsumsi lemak, pola konsumsi manis, pola aktivitas, tingkat kecemasan serta konsumsi rokok. Selanjutnya data yang telah diperoleh tersebut dianalisis bivariat menggunakan uji chi square dan uji fisher serta selanjutnya dilakukan uji multivariat dengan menggunakan regresi logistik. Analisis data ini dilakukan dengan menggunakan SPSS for Windows 20.

\section{HASIL PENELITIAN}

Penyajian hasil penelitian ditampilkan dengan tabel yang menggambarkan distribusi prosentase karakteristik responden dan pola hidup responden, serta hubungan antara karakteristik responden dan pola hidup responden dengan terjadinya peningkatan tekanan darah sistolik pada penderita hipertensi. Hasil karakteristik responden didapatkan bahwa terbanyak berusia $>=51$ tahun $(61,9 \%)$, berjenis kelamin perempuan $(71,4 \%)$, mempunyai IMT normal $(76,2 \%)$, tidak mempunyai riwayat keluarga $(83,3$ $\%)$, sering mengkonsumsi lemak $(66,7 \%)$, sering mengkonsumsi manis (90,5 \%), melakukan olahraga (76,2 \%), jarang mengalami kecemasan (83,3 \%), dan bukan termasuk dalam perokok $(73,8 \%)$. Hal ini seperti tertera pada tabel 1. 


\section{Karakteristik dan Pola Hidup Penderita Hipertensi}

Tabel 1 Karakteristik Penderita Hipertensi di Desa Trenyang RW 09 Sumberpucung Malang

\begin{tabular}{llcc}
\hline & Karakteristik Responden & $\mathrm{n}$ & $\%$ \\
\hline \multirow{2}{*}{ Usia } & $<=50$ tahun & 16 & 38,1 \\
& $>=51$ tahun & 26 & 61,9 \\
\hline \multirow{2}{*}{ Jenis Kelamin } & Perempuan & 30 & 71,4 \\
& Laki - Laki & 12 & 28,6 \\
\hline \multirow{2}{*}{ Indeks Massa Tubuh } & Normal & 32 & 76,2 \\
& Tidak Normal & 10 & 23,8 \\
\hline Riwayat Keluarga & Tidak Mempunyai & 35 & 83,3 \\
& Mempunyai Riwayat & 5 & 11,9 \\
\hline Pola Konsumsi Lemak & Jarang & 14 & 33,3 \\
& Sering & 28 & 66,7 \\
\hline Pola Konsumsi Manis & Jarang & 4 & 9,5 \\
& Sering & 38 & 90,5 \\
\hline Pola Aktivitas & Melakukan Olahraga & 32 & 76,2 \\
& Tidak Melakukan Olahraga & 10 & 23,8 \\
\hline Tingkat Kecemasan & Jarang & 35 & 83,3 \\
& Sering & 7 & 16,7 \\
\hline Konsumsi Rokok & Bukan Perokok & 31 & 73,8 \\
& Perokok & 11 & 26,2 \\
\hline Tekanan Darah Sistolik & $140-159 \mathrm{mmHg}$ & 21 & 50 \\
& $>=160 \mathrm{mmHg}$ & 21 & 50 \\
\hline
\end{tabular}

(Sumber : Data Primer, 2016)

Berdasarkan tabel 1 terlihat bahwa karakteristik responden terbanyak berusia $>=51$ tahun $(61,9 \%)$, berjenis kelamin perempuan $(71,4 \%)$, mempunyai IMT normal $(76,2 \%)$, tidak mempunyai riwayat keluarga $(83,3 \%)$, sering mengkonsumsi lemak $(66,7 \%)$, sering mengkonsumsi manis $(90,5 \%)$, melakukan olahraga $(76,2$ $\%)$, jarang mengalami kecemasan (83,3 $\%)$, dan bukan termasuk dalam perokok $(73,8 \%)$.

\section{Hasil Analisis Faktor - Faktor yang Diduga Menjadi Prediktor Terjadinya Peningkatan Tekanan Darah Sistolik Pada Penderita Hipertensi}

Untuk mengetahui faktor - faktor yang diduga menjadi prediktor terjadinya peningkatan tekanan darah sistolik pada penderita hipertensi, dilakukan uji statistik bivariat terlebih dahulu menggunakan analisis uji chi-square dan uji fisher dengan hasil seperti yang tertera pada tabel 2 dan 3. Berdasarkan pada tabel 2 , Indeks Massa Tubuh (IMT) penderita hipertensi mempunyai hubungan yang signifikan terhadap peningkatan tekanan darah sistolik pada penderita hipertensi dengan $p$-value sebesar 0,07 . Pada tabel 3 dapat diketahui bahwa riwayat keluarga dan pola konsumsi manis mempunyai hubungan dengan terjadinya peningkatan tekanan darah sistolik pada penderita hipertensi dengan hasil $p$-value 0,03 untuk riwayat keluarga dan 0,05 untuk pola konsumsi manis. Dari hasil uji chi square dan uji fisher, didapatkan tiga variabel yang mempunyai hubungan signifikan dengan terjadinya peningkatan tekanan darah sistolik, yaitu variabel IMT, riwayat keluarga dan pola konsumsi manis. Selanjutnya ketiga variabel tersebut dilakukan uji regresi logistik. Hasil uji regresi logistik didapatkan bahwa variabel yang paling berpengaruh terhadap peningkatan tekanan darah sistolik adalah riwayat keluarga dengan $p$-value sebesar 0,26 . Selanjutnya variabel IMT dengan $p$ value 0,47 dan variabel pola konsumsi manis dengan $p$-value 0,5 . 
Tabel 2 Hasil analisis uji Chi Square Hubungan Antara Usia, Jenis Kelamin, IMT, Pola Konsumsi Lemak, Pola Aktivitas dan Konsumsi Rokok Dengan Terjadinya Peningkatan Tekanan Darah Sistolik Pada Penderita Hipertensi

\begin{tabular}{|c|c|c|c|c|c|c|c|c|c|}
\hline & & \multicolumn{4}{|c|}{ Tekanan Darah Sistolik } & \multirow[t]{3}{*}{ Nilai $p$} & \multirow[t]{3}{*}{ OR } & \multicolumn{2}{|c|}{$\mathrm{Cl} 95 \%$} \\
\hline & & \multicolumn{2}{|c|}{$\begin{array}{c}140-159 \\
\mathrm{mmHg}\end{array}$} & \multicolumn{2}{|c|}{$\begin{array}{c}>160 \\
\mathrm{mmHg} \\
\end{array}$} & & & & \\
\hline & & $\mathrm{n}$ & $\%$ & $\mathrm{~N}$ & $\%$ & & & MIn & Mak \\
\hline \multirow[t]{2}{*}{ Usia } & $<50$ tahun & 8 & 50 & 8 & 50 & 1,000 & 1,000 & 0,288 & 3,475 \\
\hline & $>50$ tahun & 13 & 50 & 13 & 50 & & & & \\
\hline \multirow[t]{2}{*}{ Jenis Kelamin } & Perempuan & 16 & 53,3 & 14 & 46,7 & 0,733 & 1,600 & 0,413 & 6,193 \\
\hline & Laki - Laki & 5 & 41,7 & 7 & 58,3 & & & & \\
\hline \multirow{2}{*}{$\begin{array}{l}\text { Indeks Massa } \\
\text { Tubuh (IMT) }\end{array}$} & Normal & 19 & 59,4 & 13 & 40,6 & 0,07 & 5,846 & 1,065 & 32,082 \\
\hline & Tidak Normal & 2 & 20 & 8 & 80 & & & & \\
\hline \multirow{2}{*}{$\begin{array}{l}\text { Pola } \\
\text { Konsumsi } \\
\text { Lemak } \\
\end{array}$} & Jarang & 8 & 57,1 & 6 & 42,9 & 0,743 & 1,538 & 0,422 & 5,606 \\
\hline & Sering & 13 & 46,4 & 15 & 53,6 & & & & \\
\hline \multirow[t]{2}{*}{ Pola Aktivitas } & $\begin{array}{l}\text { Melakukan } \\
\text { Olahraga }\end{array}$ & 16 & 50 & 16 & 50 & 1,000 & 1,000 & 0,242 & 4,138 \\
\hline & $\begin{array}{l}\text { Tidak } \\
\text { Melakukan } \\
\text { Olahraga }\end{array}$ & 5 & 50 & 5 & 50 & & & & \\
\hline \multirow[t]{2}{*}{$\begin{array}{l}\text { Konsumsi } \\
\text { Rokok }\end{array}$} & Bukan Perokok & 16 & 51,6 & 15 & 48,4 & 1,000 & 1,280 & 0,322 & 5,088 \\
\hline & Perokok & 5 & 45,5 & 6 & 54,5 & & & & \\
\hline
\end{tabular}

(Sumber : Data Primer, 2016)

Tabel 3 Hasil analisis uji Fisher Hubungan Antara Riwayat Keluarga, Pola Konsumsi Manis, dan Tingkat Kecemasan Dengan Terjadinya Peningkatan Tekanan Darah Sistolik Pada Penderita Hipertensi

\begin{tabular}{|c|c|c|c|c|c|c|c|c|c|}
\hline & & \multicolumn{4}{|c|}{ Tekanan Darah Sistolik } & \multirow[t]{2}{*}{ Nilai $p$} & \multirow[t]{2}{*}{ OR } & \multicolumn{2}{|c|}{$\mathrm{Cl} 95 \%$} \\
\hline & & & $\begin{array}{l}-159 \\
\mathrm{Hg}\end{array}$ & & $\begin{array}{l}60 \\
\mathrm{Hg}\end{array}$ & & & & \\
\hline \multirow[t]{2}{*}{$\begin{array}{l}\text { Riwayat } \\
\text { Keluarga }\end{array}$} & $\begin{array}{l}\text { Tidak } \\
\text { Mempunyai } \\
\text { Riwayat }\end{array}$ & 16 & 45,7 & 19 & 54,3 & 0,03 & 0,457 & 0,319 & 0,656 \\
\hline & $\begin{array}{l}\text { Mempunyai } \\
\text { Riwayat }\end{array}$ & 5 & 100 & 0 & 0 & & & & \\
\hline \multirow[t]{2}{*}{$\begin{array}{l}\text { Pola } \\
\text { Konsumsi } \\
\text { Manis } \\
\end{array}$} & Jarang & 4 & 100 & 0 & 0 & 0,05 & 2,235 & 1,570 & 3,183 \\
\hline & Sering & 17 & 44,7 & 21 & 55,3 & & & & \\
\hline \multirow[t]{2}{*}{$\begin{array}{l}\text { Tingkat } \\
\text { Kecemasan }\end{array}$} & Jarang & 18 & 51,4 & 17 & 48,6 & 0,50 & 1,412 & 0,275 & 7,257 \\
\hline & Sering & 3 & 42,9 & 4 & 57,1 & & & & \\
\hline
\end{tabular}




\section{PEMBAHASAN}

Peningkatan tekanan darah sistolik pada penderita hipertensi dipengaruhi oleh beberapa faktor. Dalam penelitian ini didapatkan bahwa terdapat tiga faktor yang berhubungan yaitu riwayat keluarga, Indeks Massa Tubuh (IMT) dan konsumsi makanan manis.

Riwayat keluarga dengan hipertensi mempunyai pengaruh yang signifikan terhadap kejadian hipertensi. Seringkali penderita hipertensi tidak mengetahui bahwa mereka mempunyai riwayat keluarga dengan hipertensi. Dilaporkan bahwa seseorang yang teridentifikasi tidak mengetahui adanya riwayat keluarga dengan hipertensi, justru mempunyai tekanan darah sistolik yang lebih tinggi dibandingkan dengan mereka yang tidak mempunyai riwayat keluarga (Wandeler G et al, 2009). Sehingga hal ini menjadi sangat penting bahwa upaya promotif dalam rangka menurunkan kejadian hipertensi adalah dengan cara memberikan pendidikan kesehatan kepada keluarga yang mempunyai riwayat keluarga dengan hipertensi. Dengan dijadikannya keluarga dengan riwayat hipertensi sebagai target dalam promosi kesehatan, harapannya akan terjadi upaya preventif secara dini dalam rangka untuk meminimalkan kemungkinan terjadinya hipertensi. Akan tetapi seringkali masyarakat kurang sadar terhadap status kesehatan mereka. Sehingga mereka tidak mengetahui bahwa di dalam keluarga mereka mempunyai riwayat keluarga dengan hipertensi. Hal ini menjadi sangat penting untuk dikembangkan sebuah strategi ataupun alat skrining yang dapat digunakan untuk mendeteksi secara dini adanya riwayat penyakit dalam keluarga sehingga akan dapat meningkatkan kesadaran terhadap status kesehatan dirinya dan keluarganya (Janssens et al, 2012).

Riwayat keluarga dapat dijadikan sebagai alat skrining yang sangat berguna dalam mengkaji dan memanajemen resiko terjadinya penyakit tidak menular, salah satunya yaitu penyakit hipertensi (Jufen Liu et al, 2014). Deteksi dini terhadap penyakit hipertensi ini merupakan peluang bagi tenaga kesehatan untuk memberikan pendidikan kesehatan secara langsung kepada keluarga. Pendidikan kesehatan utamanya ditujukan untuk memberikan pengetahuan dan pemahaman tentang pentingnya merubah perilaku hidup sehat seperti olahraga maupun mengontrol dan menjaga konsumsi makanan yang sehat (Marianne AB et al, 2001).

Tekanan darah juga sangat erat hubungannya dengan status IMT seseorang (Hof, Michel HP et al, 2013). Status IMT yang berlebih, menjadi salah satu prediktor yang dapat menyebabkan peningkatan tekanan darah sistolik dan diastolik sehingga hal ini akan mengakibatkan terjadinya hipertensi pada seseorang. Hal ini utamanya terjadi pada seorang perempuan ( $\mathrm{K}$ Kristjansson JA et al, 2003). Berdasarkan hal tersebut dapat diketahui bahwa seorang perempuan dengan kondisi obesitas sangat beresiko mengalami peningkatan tekanan darah sistolik dan diastolik. Pada seseorang dengan obesitas, peningkatan kadar kolesterol darah dalam tubuhnya akan mempengaruhi status IMT (Rapsomaniki Eleni ei al, 2014) . Disisi lain, penelitian yang telah dilakukan oleh Zuhal Gundogdu (2008), menyatakan bahwa terdapat hubungan yang signifikan antara status IMT dengan tekanan darah seseorang baik pada laki - laki dan pada perempuan (Gundogdu Z, 2008).

Peningkatan tekanan darah sistolik seseorang juga dapat dihubungkan dengan kebiasaan perilaku konsumsi makanan yang tidak sehat seperti mengkonsumsi makanan manis. Kebiasaan perilaku mengkonsumsi makanan manis dapat menyebabkan peningkatan tekanan darah seseorang (Di Zeng et al, 2010). Konsumsi makanan manis yang berlebihan akan menyebabkan peningkatan kadar glukosa dan fruktuso yang berlebihan di dalam darah sehingga hal ini akan mempengaruhi metabolisme di dalam tubuh dan kesehatan dinding pembuluh darah. Kandungan glukosa dan fruktosa yang tinggi menyebabkan adanya gangguan signal insulin dalam tubuh, meningkatkan terjadinya lipogenesis serta menyebabkan terjadinya kerusakan homeostasis oembuluh darah (Siervo M et al, 2013). Hal ini sesuai dengan hasil penelitian ini 
didapatkan bahwa terdapat hubungan yang signifikan antara pola konsumsi makanan manis dengan terjadinya peningkatan tekanan darah sistolik pada penderita hipertensi ( $p$-value 0,05). Sehingga hal ini menjadi sangat penting bagi penderita hipertensi untuk mengurangi konsumsi makanan manis, karena penurunan konsumsi makanan manis dapat menurunkan tekanan darah seseorang (Di Zeng et al, 2010).

\section{KESIMPULAN}

Faktor yang berhubungan dengan terjadinya peningkatan tekanan darah sistolik yaitu Indeks Massa Tubuh (IMT),

\section{DAFTAR PUSAKA}

Bell Kayce,Twiggs june and Olin Bernie R. 2015. Hypertension : The Silent Killer: Updated JNC-8 Guideline Recommendations. Alabama Pharmacy Association

Bickley. Lynn S.2015.Pemeriksaan Fisik \& Riwayat Kesehatan.Jakarta : EGC

Di Zeng,Qiang-sun Zheng,Dong-bo Ou. 2010.Dietary Therapy in Hypertension. The New England Journal of Medicine.

Gundogdu,Zuhal.2008.Relationship between BMI and blood pressure in girls and boys.Public Health Nutrition. 11 (10). 1085 - 1088

Hof, Michel HP;Vrijkotte,Tanja GM;Hoog, L Ade;Eijsden,Manon van; Zwinderman,Aeilko H.2013. Association between Infancy BMI Peak and Body Composition and Blood Pressure at Age 5-6 Years. PLoS One. Vol 8 Issue 12

Janssens, A. Cecile J.W.Henneman, Lidewij; Detmar, Symone B.; Khoury, Muin J.; Steyerberg, Ewout W.2012.Accuracy of self-reported family history is strongly influenced by the accuracy of self-reported personal health status of relatives.Journal of Clinical Epidemiology 65. 82-89

Jawa Pos. 2016.Gagal Jantung Kian Mengancam.Malang : Jawa Pos

Jufen Liu,Michikazu Sekine,Takashi Tatsuse, Shimako Hamanishi,Yuko riwayat keluarga dengan hipertensi, dan pola konsumsi makanan manis. Hasil penelitian ini menunjukkan bahwa pentingnya bagi seorang penderita hipertensi untuk menjaga pola hidup sehat dengan mengontrol makanan sehari - hari antara lain membatasi konsumsi makanan manis, membatasi konsumsi makanan berlemak, dan berolahraga untuk menjaga IMT dalam batas normal serta menjaga pola hidup sehat yang lain seperti mengontrol kecemasan serta menghindari konsumsi rokok. Dengan berperilaku hidup sehat, harapannya tekanan darah menjadi terkontrol sehingga terhindar dari berbagai macam komplikasi yang dapat ditimbulkannya.

Fujimura, and Xiaoying Zheng. 2014. Family History of hypertension and the Risk of Overweight in Japanese Children: Results From the Toyama Birth Cohort Study.J Epidemiology. $304-311$

K Kristjansson JA Sigurdsson L Lissner V Sundh and C Bengtsson.2003. Blood pressure and pulse pressure development in a population sample of women with special reference to basal body mass and distribution of body fat and their changes during 24 years. International Journal of Obesity. Page 128 - 133

Marianne AB, Van der Sande,Walfaren Gijs EL,Miligan Paul,Banya Winston AS,Ceesay Sana M,Nyan Ousma A, McAdam Keith PWJ.2001.Family History : an opportunity for early interventions and improved control of hypertension,obesity and diabetes. Bulletin of the World Health Organization. $321-328$

Pusat Data dan Informasi Kementerian Kesehatan RI.2013.Situasi Kesehatan Jantung. Jakarta : Kementerian Kesehatan RI

Rapsomaniki Eleni,Timmis Adam, George Julie, Rodriguez Mar Pujades, Shah Anoop D, Denaxas Spiros, White lan R, Caulfi Mark J, Deanfi John E, Smeeth Liam, Williams Bryan, Hingorani A, Hemingway Harry. 2014. Blood pressure and incidence 
of twelve cardiovascular diseases: lifetime risks, healthy life-years lost, and age-specifi $c$ associations in 1.25 million people. Lancet. Vol 383. 1899-911

Saputra Lyndon. 2014. Visual Nursing Kardiovaskuler. Editor : Aria Wahyuni. Jakarta : Binarupa Aksara

Siervo M, Montagnese C, Mathers JC, Soroka KR, Stephan B, Wells J. 2013. Sugar consumption and global prevalence of obesity and hypertension: an ecological analysis. Public Health Nutrition. 587-596. doi:10.1017/S1368980013000141

Wandeler G,Paccaud F,Weider PV,Waeber G,Mooser V,Bochud M.2009.Strength of Family History in Predicting Levels of Blood Pressure,Plasma Glucose and Cholesterol.Public Health Genomics.143-154. 